Research Article

\title{
Optimum Design for Mechanical Structures and Material Properties of the Dual-Elbow-Bar Mechanism
}

\author{
Weiguo Lin, Chen Zhou, and Weijun Huang \\ College of Engineering, Huazhong Agricultural University, Wuhan 430070, China \\ Correspondence should be addressed to Weiguo Lin; linweiguo@mail.hzau.edu.cn
}

Received 14 August 2014; Accepted 8 October 2014

Academic Editor: Yan Yang

Copyright (C) 2015 Weiguo Lin et al. This is an open access article distributed under the Creative Commons Attribution License, which permits unrestricted use, distribution, and reproduction in any medium, provided the original work is properly cited.

\begin{abstract}
According to the kinematic equation of the die-cutting machine with the dual-elbow-bar mechanism, the angular acceleration curve figure can be obtained exactly through the analysis of MATLAB program when the die-cutting machine runs at the highest speed $(6000 \mathrm{r} / \mathrm{h})$. The material properties of the cam driving mechanism are analyzed by QFD (Quality Function Deployment) method, and the optimum design project is presented based on conjugate cam driving mechanism. The reverse design and the outline of conjugate cam mechanism are obtained by MATLAB program. The kinematical form of optimized design conjugate cam driving mechanism is simulated and analyzed by ADAMS software. The results show that the optimum design mechanism could raise the highest speed of the die-cutting machine up to $7500 \mathrm{r} / \mathrm{h}$ and improve the overall performance of the machine.
\end{abstract}

\section{Introduction}

In printing and packaging machinery, the dual-elbow-bar driving mechanism is the most important and essential part of die-cutting machine. Its motion and force conditions directly affect the precision of die-cutting, the speed of cutting, and the machine's stability and reliability; therefore, the kinematics and dynamics analysis of the dual-elbow-bar mechanism is crucial [1].

In the hope of solving the existing problems of dualelbow-bar mechanism, many scholars had carried out studies from the perspective of kinematics, dynamics, and the performance of the optimal design, and some had made remarkable achievement. Xie and Zou presented a method to analyze the dynamic response of the platen die-cutter, which combined the finite element analysis of the die-cutting force and the dynamic simulation of the dual-elbow-bar mechanism. Meanwhile, the analysis made it possible to calculate the utmost speed and the utmost cutting force of platen die-cutter [2]. Li and Cheng solved the analytic equation about motionstand ratio of double-bar chains, die plate stroke, and bar dimension on the basis of a simplified model that overlooked minor factor [3]. Zhang et al. analyzed the motion of the dual-elbow-bar mechanism based on the loop method [4].
Yong et al. introduced the method of conversion mechanism to solve the dual-elbow-bar group movement and considered that the senior bar group reduced to lower rod group, which reduces the computational complexity of motion analysis [5]. Cheng and Wang analyzed and calculated the reliability of the elbow-bar mechanism of automatic die-cutting machine by taking the original errors as stochastic variables [6]. Yanbin et al. analyzed elbow-bar framework of the die-cutting system of blocking die-cutter with numerical method and designed an experiment to verify the mechanism property of die-cutting system [7]. Qun and Zhimin modeled and emulated the dual-elbow-bar mechanism of the die-cutting machine using SolidWorks and analyzed the movement characters of some component [8]. Zhao and Li built the simulation model of the dual-elbow-bar mechanism of die-cutting machine based on ADAMS, which performed a simulation analysis on dualelbow-bar mechanism and worked out the motion law of the dual-elbow-bar mechanism [9]. Fan and Ding described the shiftlessness of the high-speed rotary die-cutting machine and its control system by comparing various transmission and analyses of certain programs [10].

According to the existing research, there are still some deficiencies in design of die-cutting machine. The cause of this situation is as follows. (1) It mainly relies on the 


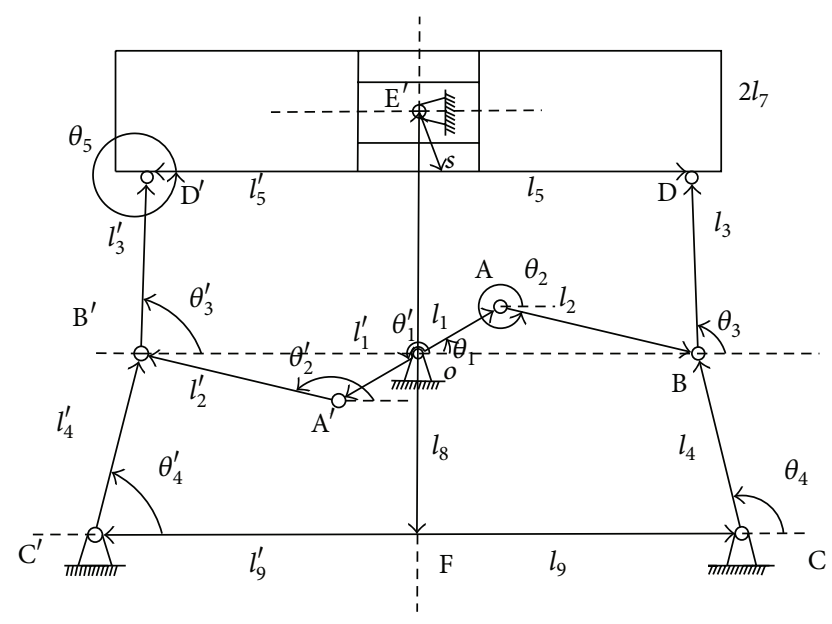

FIGURE 1: The dual-elbow-bar driving mechanism of die-cutting machine.

traditional design method, which causes low processing efficiency, production quality, and accuracy and poor stability. (2) Material selection is dependent on experience, lacking of guidance on using the QFD tool. (3) The virtual simulation technology of optimization design method in the design of die-cutting machine is still not mature.

The main die-cutting mechanism of die-cutting machine diagram is a ten-bar mechanism, which is complex and symmetrical as showed in Figure 1. In Figure $1, \mathrm{AA}^{\prime}$ is the driving crank, $\mathrm{AB}$ and $\mathrm{A}^{\prime} \mathrm{B}^{\prime}$ are the connecting rods, $\mathrm{BC}$ and $\mathrm{B}^{\prime} \mathrm{C}^{\prime}$ are the lower toggle rods, $\mathrm{BD}$ and $\mathrm{B}^{\prime} \mathrm{D}^{\prime}$ are the upper toggle rods, and $\mathrm{DD}^{\prime}$ is the cutting platform. Since the mechanism is symmetrical, from the right side, it can be actually seen as a combination that is composed of crankrocker mechanism and the crank slider mechanism, in which the crank-rocker mechanism consists of crank drive parts where $\mathrm{BC}$ serves as a rocker and the crank slider mechanism consists of a driving part (DB) and die-cutting machine platform for slide block.

\section{Kinematic Analysis of the \\ Die-Cutting Machine with the Dual-Elbow-Bar Mechanism}

Considering that the driving mechanism of dual-elbow-bar cutting machine is 10th-rod and 3rd-level institutions, it is accurate and simple to use plural vector method to analyze and calculate the law of motion rod. First, we need to establish the displacement closed vector equation of the rods; second, we could convert them into nonlinear equations by Euler's formula; in the end, we can solve the equations to get the rule of movement by MATLAB programming [11, 12].

Based on Figure 1, we can set up the displacement closed vector equations of two-level institutions. It is as follows:

$$
\begin{gathered}
\overrightarrow{l_{1}}+\overrightarrow{l_{2}}=\overrightarrow{l_{8}}+\overrightarrow{l_{9}}+\overrightarrow{l_{4}}, \\
{\overrightarrow{l_{1}}}^{\prime}+{\overrightarrow{l_{2}}}^{\prime}={\overrightarrow{l_{8}}}^{\prime}+{\overrightarrow{l_{9}}}^{\prime}+\vec{l}_{4}^{\prime} .
\end{gathered}
$$

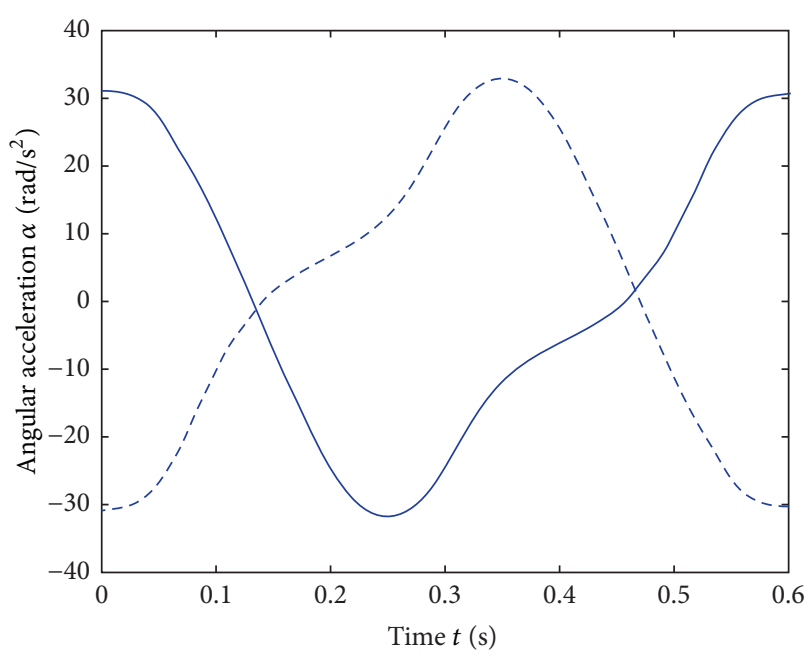

Figure 2: The angular acceleration of $\mathrm{BC}$ and $\mathrm{B}^{\prime} \mathrm{C}^{\prime}$.

Then carry out (1) in the plural form expression with Euler's formula, in which the real parts and imaginary parts are equal:

$$
\begin{gathered}
l_{1} \cos \theta_{1}+l_{2} \cos \theta_{2}=l_{8} \cos \frac{3 \pi}{2}+l_{9}+l_{4} \cos \theta_{4}, \\
l_{1} \sin \theta_{1}+l_{2} \sin \theta_{2}=l_{8} \sin \frac{3 \pi}{2}+l_{4} \sin \theta_{4}, \\
l_{1} \cos \theta_{1}^{\prime}+l_{2} \cos \theta_{2}^{\prime}=l_{8} \cos \frac{3 \pi}{2}+l_{9}+l_{4} \cos \theta_{4}^{\prime}, \\
l_{1} \sin \theta_{1}^{\prime}+l_{2} \sin \theta_{2}^{\prime}=l_{8} \sin \frac{3 \pi}{2}+l_{4} \sin \theta_{4}^{\prime} .
\end{gathered}
$$

Assuming that the maximum cutting pressure of diecutting machine is 300 tons, the highest cutting speed is 6,000 tickets/hour, the precision of die-cutting is $0.1 \mathrm{~mm}$, the stroke of die-cutting platform is $25 \mathrm{~mm}$, and the host power is $15 \mathrm{KW}$. Based on the result of (2), we can establish the rod kinematics equation and solve the motion equations of mechanism by MATLAB numerical analysis software programming. At last, variation curves of angular acceleration can be obtained in MATLAB drawing circumstance of double toggle components within a single cycle.

As showed in Figure 2, when the maximum angular acceleration has reached nearly $30 \mathrm{rad} / \mathrm{s}^{2}$, the connecting rod is the weak parts of the mechanism, which has a bigger impact and greater effect on its fatigue strength. As shown in Figure 3, when $\mathrm{BD}$ and $\mathrm{B}^{\prime} \mathrm{D}^{\prime}$ rod that connect with the cutting platform reach the top of the cutting, it will have an impact on the cutting platform with the acceleration more than $40 \mathrm{rad} / \mathrm{s}^{2}$. Since the cutting platform mechanism is large in size and weight, this means the platform has great inertia force in the process of movement that poses a great impact on the driving mechanism and affects the kinematic precision seriously. 
TABLE 1: The function requirements with alloy composition.

\begin{tabular}{lccccc}
\hline Functional requirements & Strength & Plasticity & Toughness & $\begin{array}{c}\text { Corrosion } \\
\text { resistance }\end{array}$ & Weldability \\
\hline Alloy composition & $\mathrm{C} \mathrm{Mn} \mathrm{Nb} \mathrm{Cr}$ & $\mathrm{C} \mathrm{Mn} \mathrm{Nb}$ & $\mathrm{C} \mathrm{Nb} \mathrm{Mn} \mathrm{Ti}$ & $\mathrm{C} \mathrm{P} \mathrm{S} \mathrm{Cu}$ & $\mathrm{C} \mathrm{Mn} \mathrm{S} \mathrm{P}$ \\
& $\mathrm{S} \mathrm{P}$ & $\mathrm{S} \mathrm{P}$ & $\mathrm{S} \mathrm{P} \mathrm{Cr}$ & $\mathrm{Cr} \mathrm{Ni} \mathrm{Al} \mathrm{Cu} \mathrm{Ni} \mathrm{Cr}$ \\
\hline
\end{tabular}

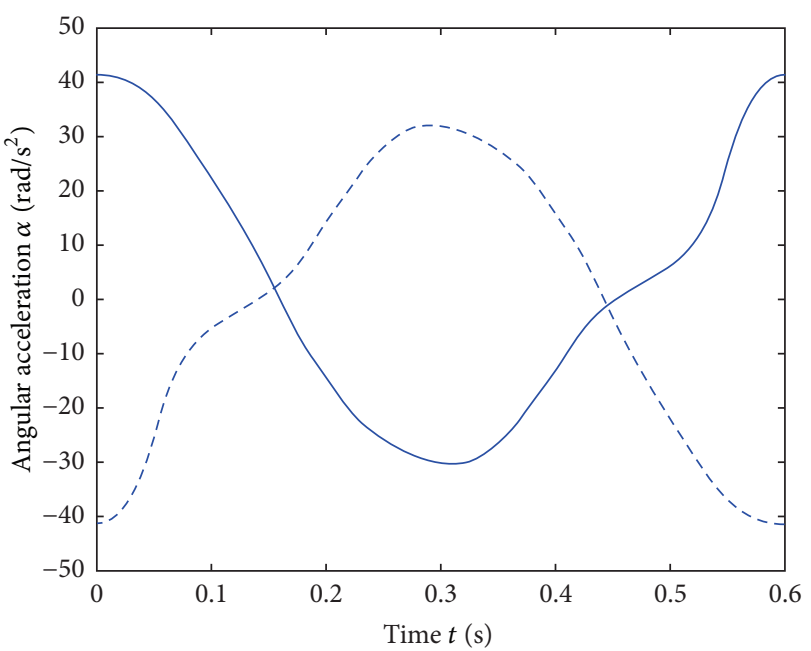

FIgUre 3: The angular acceleration of $\mathrm{BD}$ and $\mathrm{B}^{\prime} \mathrm{D}^{\prime}$.

\section{Optimum Design for Mechanism and Material Properties of the Driving Mechanism}

The motion of dual-elbow-bar has a great influence on the performance of the machine. When reaching the peak acceleration, it will produce a larger impact load. And then, the motion of cutting platform does not conform to the process requirements. All about these conclusions will serve as the parameter of structural optimization design. At present, we need to find a new driving mechanism to replace the original, which can improve the motion characteristics, so that one not only can achieve the cutting process requirement but also makes the mechanism as simple as possible. In the design of cam mechanism, dual-elbow-bar part should be retained as much as possible so that the contour surface can avoid bearing larger load.

(1) First of all, the material of the cam's alloy composition should be confirmed based on the working properties. The traditional design is often preceded designed chemical composition of alloy steel by experience and then process design. However, the lack of design in accordance with the axiom meets neither the design axiom between functional domain and the physical domain nor the design between the physical domain and process domain [13]. After QFD (Quality Function Deployment) transforming, the function demands are strength, plasticity, toughness, corrosion resistance, and weldability.

According to the experience, the alloy composition and other influential components are listed in Table 1.

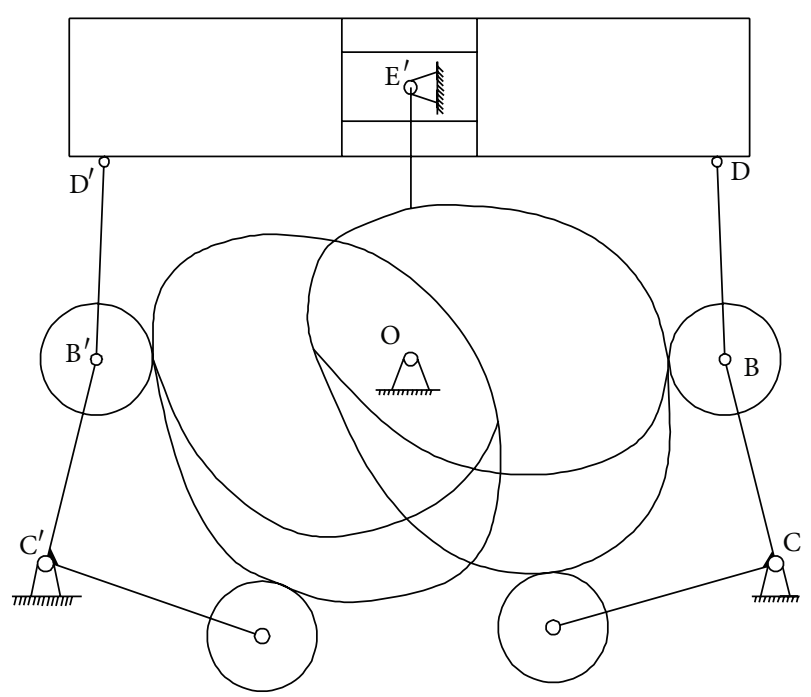

Figure 4: Conjugate cam driving mechanism.

The design method mentioned above can be represented by axiomatic design in Formula (3) as follows:

$$
\begin{gathered}
\left\{\begin{array}{c}
\text { strength } \\
\text { plasticity } \\
\text { impact energy } \\
\text { corrosion resisitance } \\
\text { weldability }
\end{array} \quad \begin{array}{c}
\text { FR2 } \\
\text { FR2 } \\
\text { FR2 }
\end{array}\right\} \\
=\left[\begin{array}{llllllllll}
1 & 0 & 1 & 0 & 0 & 1 & 1 & 1 & 0 & 1 \\
1 & 0 & 1 & 0 & 0 & 1 & 1 & 1 & 0 & 0 \\
1 & 1 & 1 & 0 & 0 & 1 & 1 & 1 & 0 & 1 \\
1 & 0 & 0 & 1 & 1 & 1 & 1 & 0 & 1 & 0 \\
1 & 0 & 1 & 1 & 1 & 1 & 1 & 0 & 0 & 1
\end{array}\right]\left[\begin{array}{c}
\mathrm{C} \text { content } \\
\mathrm{Ti} \ldots \\
\mathrm{Mn} \ldots \\
\mathrm{Ni} \ldots \\
\mathrm{Cu} \ldots \\
\mathrm{S} \ldots \\
\mathrm{P} \ldots \\
\mathrm{Nb} \ldots \\
\mathrm{Al} \ldots \\
\mathrm{Cr} \ldots
\end{array}\right] .
\end{gathered}
$$

According to the axiomatic design shown in Figure 4, in view of the functional requirement level decomposition, following the axiom of axiomatic design, the coupling of material parameters and mechanism function can be reduced; thus we can confirm the material of the cam's alloy composition as $40 \mathrm{crMo}$.

(2) Second, the motion parameters of the cutting platform should be determined as follows.

(a) Work Speed. According to the design requirements, the maximum speed of original should be increased from 6,000 


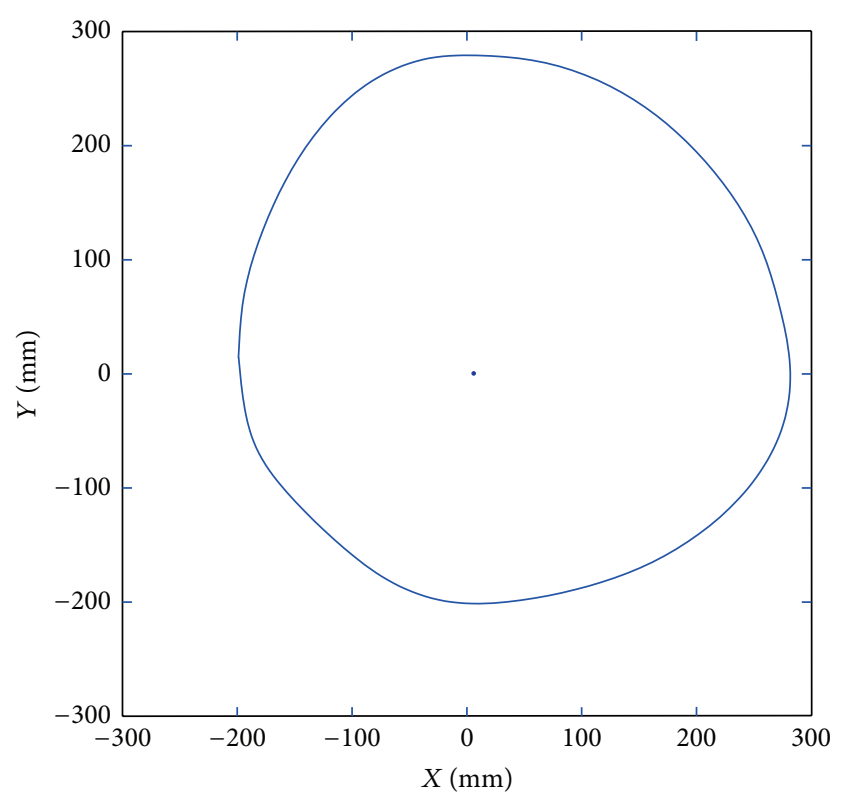

FIGURE 5: The contour curve of main cam.

tickets/hour to 7,500 tickets/hour, so a cycle experienced that $T=3600 / 7500=0.48 \mathrm{~s}$.

(b) Holding Pressure Time. Based on the process requirements, the working pressure holding time should not be less than 0.12 seconds. In this design, it is 0.16 seconds.

(c) The Maximum Acceleration of Cutting Platform. Insure that the inertia force which is conducive to the movement and avoid the large impact. The value $a=5 \mathrm{~m} / \mathrm{s}^{2}$.

(d) Lift and Return Time Distribution. For making the smooth operation of the mechanism, the lift time is equal to the return time, namely, 0.16 seconds.

(e) Working Stroke. According to the requirement, the design of working stroke is $20 \mathrm{~mm}$.

By using optimum design method to reverse the cam outline and then programming an accurate map of cam profile in the MATLAB, the cam contour line coordinates with the parameters of the equation are derived by means of coordinate transformation [14]. After each structural parameter of conjugate cam contour coordinates equations being determined, we can obtain the contour coordinates of cam rotating value in MATLAB equation, as shown in Figures 5 and 6.

The contour of the conjugate cam drawing in MATLAB is composed of a series of discrete points by the spline curve fitting. As the coordinate data of these points are saved in Workspace data file in MATLAB, we can get the threedimensional entity graph of the conjugate cam structure by calling in the coordinate data file of major and vice cam profile in SolidWorks [15].

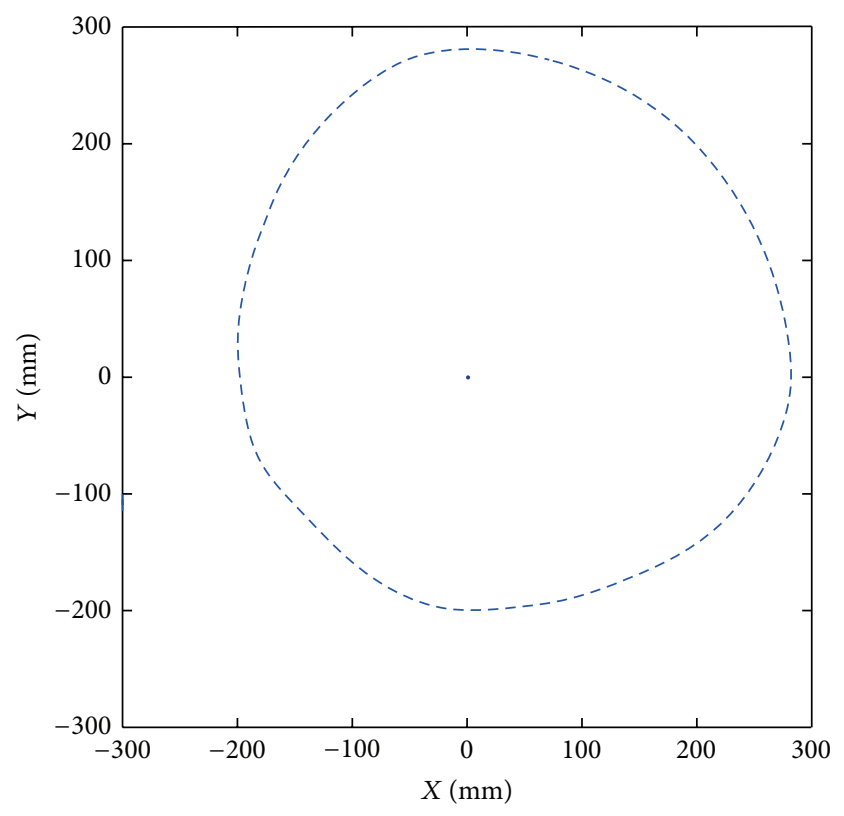

Figure 6: The contour curve of pair cam.

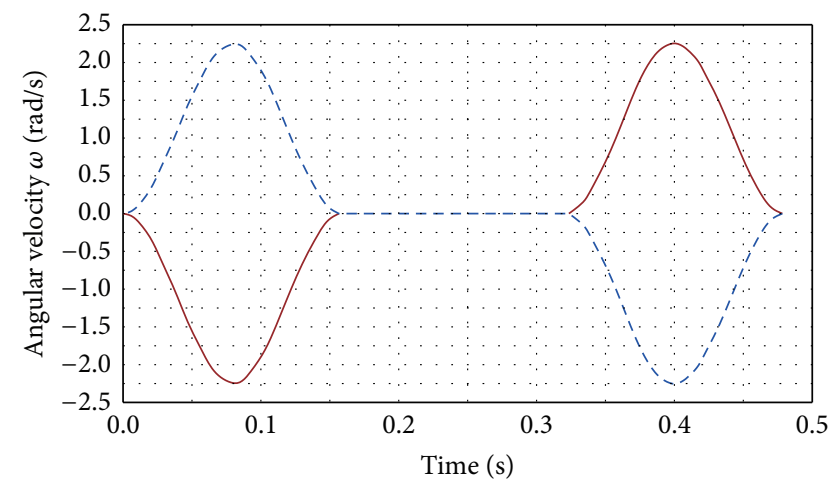

FIGURE 7: The angular velocity of $\mathrm{BC}$ and $\mathrm{B}^{\prime} \mathrm{C}^{\prime}$.

\section{Kinematics Simulation of Optimized Mechanism}

Once the geometric model that has been modeled in SolidWorks is put into ADAMS, we can start the analysis and simulation of mechanism dynamics.

The optimized mechanism is composed of upper and lower toggle, cam, cutting platform, rails, and engine base. The operating speed is 7,500 tickets/hour. Adding the speed driver for $13.08 \mathrm{rad} / \mathrm{s}$ to the primary component of the input shaft (connected with the conjugate cam), simulation time is $0.48 \mathrm{~s}$ and step is $0.001 \mathrm{~s}$.

By ADAMS simulation analysis, we get the speed and angular acceleration movement of $\mathrm{BC}$ and $\mathrm{B}^{\prime} \mathrm{C}^{\prime}$, as shown in Figures 7 and 8 . The red solid line represents $\mathrm{BC}$, and the blue dotted line represents $\mathrm{B}^{\prime} \mathrm{C}^{\prime}$. 


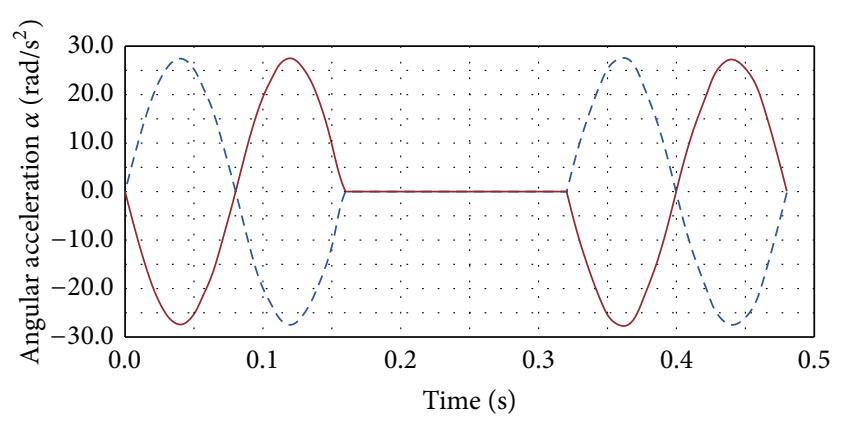

Figure 8: The angular acceleration of $\mathrm{BC}$ and $\mathrm{B}^{\prime} \mathrm{C}^{\prime}$.

\section{Conclusion}

By comparing the characteristic curve of dual-elbow-bar driving mechanism in the 6,000 tickets/hour and the conjugate cam driving mechanism in the 7,500 tickets/hour, we can get the following conclusions.

(1) Based on the QFD and axiomatic design, the material of the cam's alloy composition is confirmed as $40 \mathrm{crMo}$ which can get favorable kinematic performance.

(2) The symmetrical bars of conjugate cam driving mechanism, such as BC and $B^{\prime} C^{\prime}$ shown in Figures 7 and 8, have symmetric variation law of motion. Their speed and angular acceleration movement are smooth and continuous without mutation.

(3) The angular acceleration of the two elbow-bars of dual-elbow-bar driving mechanism is more than $40 \mathrm{rad} / \mathrm{s}^{2}$, but angular acceleration of the two elbowbars of the conjugate cam driving mechanism is less than $30 \mathrm{rad} / \mathrm{s}^{2}$, which can reduce the impact load on the die-cutting machine.

\section{Conflict of Interests}

The authors declare that there is no conflict of interests regarding the publication of this paper.

\section{Acknowledgments}

This paper is supported by National Natural Science Foundation of China (Program no. 51305152); by National Natural Science Foundation of China (Program no. 51405179); and by the Fundamental Research Funds for the Central Universities (Program no. 52902-0900206075).

\section{References}

[1] C. Xue Chao, Y. Qi, and X. Wang, "The mechanism analysis and experiment research about die-cutting pressure," Journal of Beijing Institute of Graphic Communication, vol. 19, no. 2, pp. 39-42, 2011.

[2] J. Xie and H.-J. Zou, "Dynamic analysis of the double-elbow-bar mechanism of automatic vertical platen die-cutter," Mechane Design and Research, vol. 21, no. 3, pp. 75-78, 2005.
[3] G. Li and G. Cheng, "Analysis and research of die cutting platen press mechanism and its motion compatibleness," Packaging and Food Machinery, vol. 21, no. 5, pp. 5-7, 2003.

[4] X. Zhang, S. Chai, and G. Cheng, "Motion analysis and optimum design of the dual-elbow-bar mechanism of the die cutting machine," Journal of Beijing Institute of Graphic Communication, vol. 14, no. 2, pp. 32-34, 2006.

[5] L. Yong, H. Hongyan, and C. Ganghu, "Analysis of dualelbow-bar group motion based on conversion method," Printing Engineering, vol. 3, pp. 34-37, 2007.

[6] G. Cheng and X. Wang, "Reliability analysis for kinematics accuracy on elbow-bar mechanism of automatic die cutting machine," Chinese Mechanical Engineering, vol. 18, no. 15, pp. 1786-1789, 2007.

[7] W. Yanbin, Z. Qinghai, and Z. Haiyan, "Characteristic research of elbow-bar framework of blocking die-cutter," Machine Design and Research, vol. 21, no. 1, pp. 76-78, 2005.

[8] Y. Qun and W. Zhimin, "Computer emulation of the dualelbow-bar mechanism of the die-cutting machine," Packaging Engineering, vol. 27, no. 6, pp. 191-193, 2006.

[9] X. Zhao and Y. Li, "Motion simulation of the dual-elbow-bar mechanism of the die-cutting machine based on ADAMS," Light Industry Machinery, vol. 26, no. 3, pp. 11-13, 2008.

[10] F. Fan and H. Ding, "The research and the application for the rotary die-cutting machine drive technology," in Proceedings of the International Conference on Mechanic Automation and Control Engineering (MACE '10), pp. 5914-5917, Wuhan, China, June 2010.

[11] W. Q. Cao, Linkage Analysis and Synthesis, Science Press, Beijing, China, 2002.

[12] Y. Song and D. Jia, MATLAB Numerical Analysis and Application, Mechanical Industry Press, Beijing, China, 2009.

[13] N. P. Suh, "Designing-in of quality through axiomatic design," IEEE Transactions on Reliability, vol. 44, no. 2, pp. 256-264, 1995.

[14] L. Guo and S. Guo, "Design and simulation of cam figure," Mechanical Research \& Application, vol. 18, no. 3, pp. 95-99, 2005.

[15] C. Liping, Mechanical System Dynamics Analysis and ADAMS Application Tutorial, Tsinghua University Press, Beijing, China, 2005. 

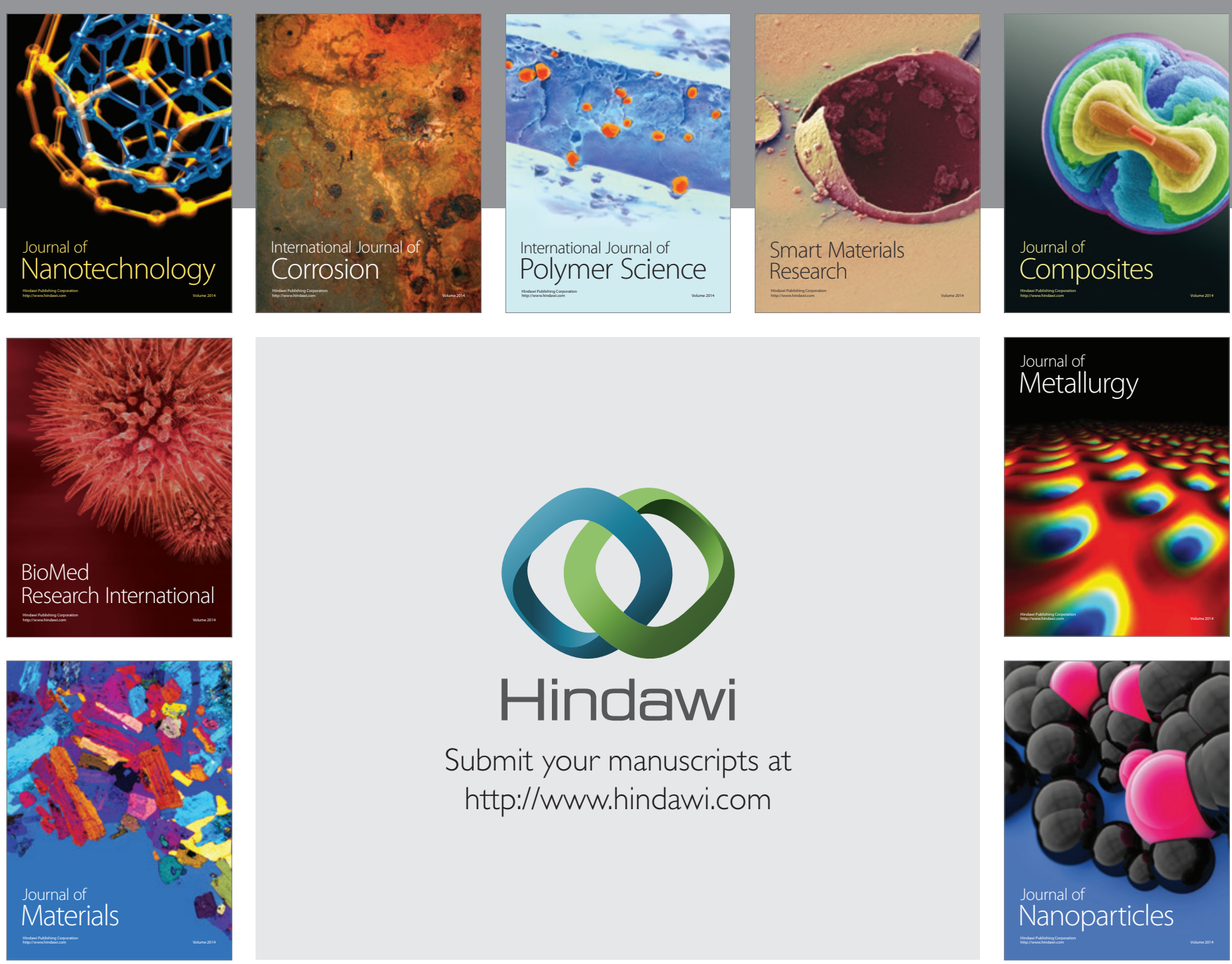

Submit your manuscripts at http://www.hindawi.com
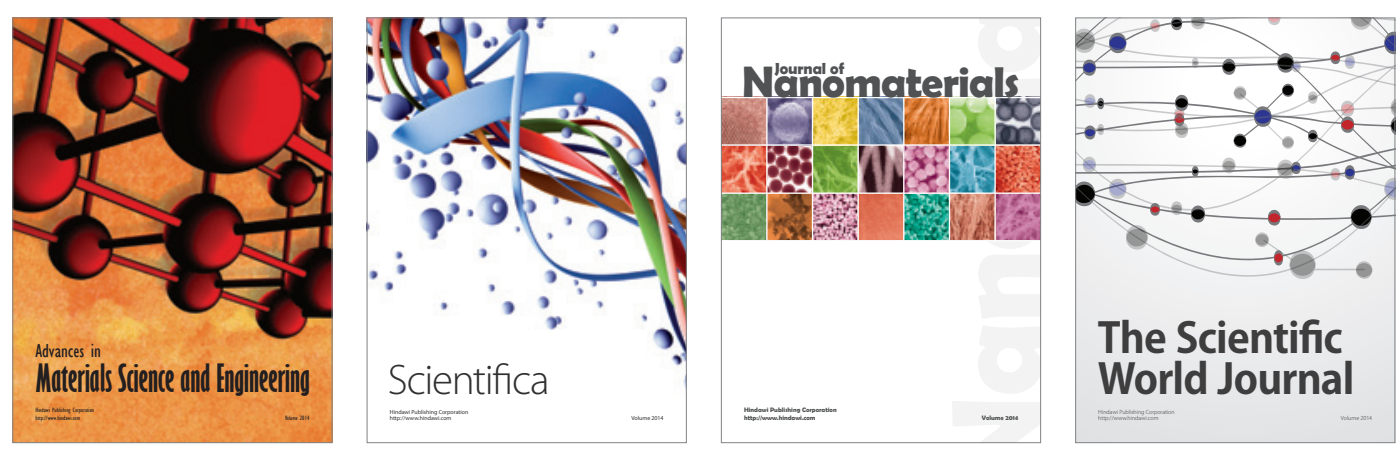

\section{The Scientific World Journal}
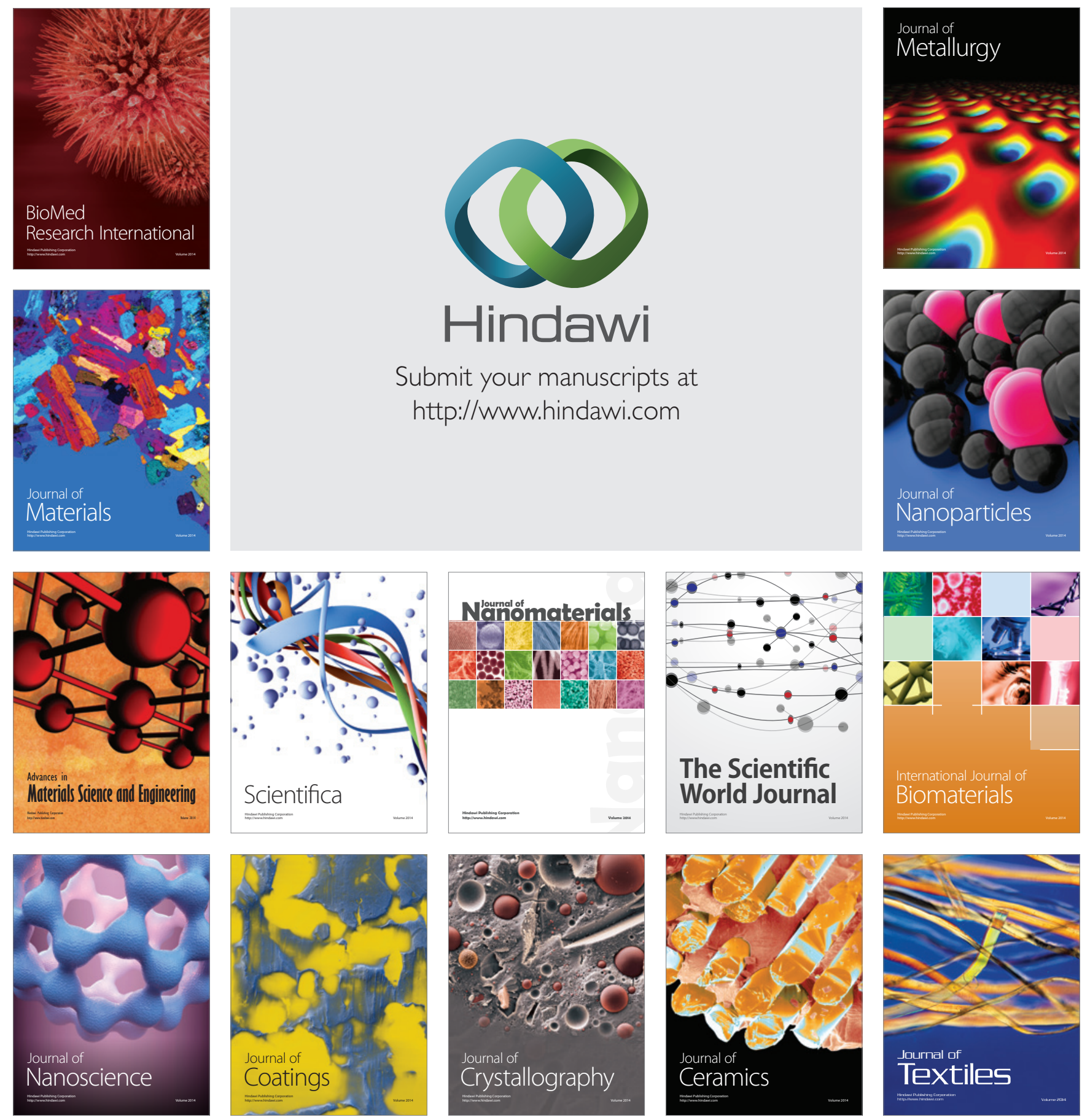